\title{
EDUCAÇÃO ESPECIAL EM TEMPOS DE EDUCAÇÃO INCLUSIVA: A IDENTIDADE DOCENTE EM QUESTÃO
}

\author{
SPECIAL EDUCATION IN TIMES OF INCLUSIVE EDUCATION: \\ THE IDENTITY OF THE TEACHER IN QUESTION \\ L'ÉDUCATION SPÉCIALE EN TEMPS DE L'ÉDUCATION INCLUSIVE : \\ L'IDENTITÉ DU PROFESSEUR EN QUESTION \\ EDUCACIÓN ESPECIAL EN TIEMPOS DE EDUCACIÓN INCLUSIVA: \\ LA IDENTIDAD DOCENTE EN CUESTIÓN
}

Maria Edith Romano Siems *

\section{RESUMO}

Neste artigo apresentamos uma pesquisa realizada no decorrer de um curso de Mestrado em Educação, na qual buscamos compreender a forma como professoras que atuam na educação de pessoas com deficiência, considerados socialmente como professores da Educação Especial, constituem sua Identidade Profissional neste momento em que as discussöes apontam para a ênfase na Educação Inclusiva. Identificamos os fatores que contribuíram nas histórias de vida dessas professoras na construção de sua identidade docente, para que se posicionassem como professores da área da Educação Especial. Tomamos como referencial teórico-metodológico a perspectiva histórico-cultural, em especial os estudos de Bakhtin e Vigotski. Nas entrevistas coletivas realizadas com um grupo de sete professoras de escolas públicas de Roraima, analisamos o processo de constituição identitária dessas professoras, considerando suas histórias de vida pessoal, acadêmica e profissional, identificando a influência marcante da atual estrutura de organização do trabalho docente em seus perfis profissionais.

Palavras-chave: Educação Especial. Formação de professores. Inclusão. Identidade docente. Profissionalidade docente.

\footnotetext{
* Mestre em Educação pela Universidade Federal de Juiz de Fora (2008). Professora Assistente da Universidade Federal de Roraima, Boa Vista - RR (msiems@uol.com.br).
} 
A Identidade Profissional Docente tem sido abordada em vários estudos em nosso país, tanto focados nos professores das séries iniciais da Educação Básica, quanto nas investigações que envolvem a constituição identitária de professores que atuam em campos específicos do saber. Esses trabalhos acompanham a evolução que os estudos acerca da Profissionalidade Docente vêm tendo em nosso país nas últimas décadas.

Do conjunto desses professores, destacamos como foco de nosso estudo os profissionais que atuam na Educação Especial, entendida em nossa legislação de ensino como modalidade educacional responsável pela educação de pessoas com necessidades especiais. Essa modalidade vem sofrendo alterações relevantes, na medida em que as políticas educacionais se encaminham no sentido da inclusão de todas as crianças em turmas do ensino regular, a chamada Educação Inclusiva, ${ }^{1}$ o que entendemos trazer implicações expressivas para os docentes que atuam prioritariamente com pessoas que apresentam peculiaridades entendidas como características das pessoas com necessidades especiais.

Neste artigo apresentamos uma pesquisa realizada no decorrer de um curso de Mestrado em Educação, na qual buscamos compreender a forma como professoras que atuam na educação de pessoas com deficiência, considerados socialmente como professores da Educação Especial, constituem sua Identidade Profissional, neste momento em que as discussōes apontam para a ênfase na Educação Inclusiva. Foram participantes da pesquisa professoras da rede pública de ensino fundamental do Município de Boa Vista, Estado de Roraima, que atuam na educação de pessoas com deficiência.

A profissão docente carrega em si a especificidade de fazer-se presente ao longo de toda a vida dos indivíduos, iniciando-se tão logo o sujeito adentre pela primeira vez o espaço escolar como aluno e alongando-se por todo o período em que o indivíduo exerça sua atividade profissional como professor. Ocorre que essa atuação se dá em um contexto social e histórico, entre indivíduos constituídos nas relaçôes sociais, entre seres que dialeticamente se constituem ao tempo em que alteram a realidade à sua volta.

Em nosso processo de trabalho, com o intuito de manter a interlocução e a coerência entre os referenciais teóricos, a metodologia e os instrumentos de pesquisa adotados, buscamos subsídios na perspectiva histórico-cultural, embasando-nos na teoria enunciativa da linguagem de Bakhtin e na teoria da construção social do conhecimento de Vigostski. Temos por objetivo identificar que fatores contribuíram nas histórias de vida das participantes de nossa pesquisa na construção de sua identidade docente, para que se posicionassem como professores da área da Educação Especial.

Apontamos inicialmente nosso entendimento acerca do conceito de Identidade Docente e alguns estudos que analisam a construção dessa Identidade; apresentamos o referencial histórico-cultural, adotado em nosso processo de pesquisa como fundamento teórico-metodológico, situando, então, os elementos que compreendemos serem constituintes das Identidades Docentes das professoras que participaram de nossa pesquisa. 
Finalmente, indicamos temáticas que, exorbitando as questões específicas de constituição identitária, denotam conflitos e contradições do campo da Educação Especial a serem aprofundados em futuros estudos.

\section{A IDENTIDADE PROFISSIONAL DOCENTE}

A docência é uma atividade profissional que se reveste de características peculiares. Envolve uma ampla gama de determinantes subjetivos, próprios das relações humanas que se estabelecem com base na linguagem, e traz consigo a particularidade de ser elemento do cotidiano de todos os profissionais desde a mais tenra idade, em um processo em que, à formação inicial, realizada nos cursos de formação inicial de professores, sobrepõem-se a vivência, as experiências e os "modelos" de professor vivenciados pelos indivíduos. Tardif e Lessard (2005, p. 35) nos alertam que a docência tem a especificidade de ser:

um trabalho cujo objeto não é constituído de matéria inerte ou de símbolos, mas de relações humanas com pessoas capazes de iniciativa e dotadas de uma certa capacidade de resistir ou de participar da ação dos professores.

Mas, o que é a Identidade Profissional do professor e como ela se estabelece? Na ótica de Gatti (1996 apud BRZEZINSKI, 2002, p. 9),

a identidade do professor é fruto de interaçóes sociais complexas nas sociedades contemporâneas e expressão sociopsicológica que interage nas aprendizagens, nas formas cognitivas, nas ações dos seres humanos. Ela define um modo de ser no mundo, num dado momento, numa dada cultura, numa história.

Placco (2006), em seu texto em que discute a aprendizagem do adulto professor, nos apresenta um conceito de formação identitária que reafirma o que constatamos nas trajetórias descritas pelas professoras ao longo das entrevistas. Em seu entendimento, a formação identitária:

É um processo de construção e desconstrução, formação e deformação, um movimento em que o docente assume formas identitárias, via processo de identificação e não-identificação com as atribuições que lhe são dadas por si mesmo e pelos outros com quem se relaciona. Nesse movimento, há constantes atos e sentimentos de pertença e não-pertença, estreitamente relacionados à subjetividade, à memória, a processos metacognitivos, aos saberes e experiências de pessoas singulares e do grupo (PLACCO, 2006, p. 21).

Essa noção de identidade afina-se com a perspectiva posta por Bakhtin e seu Círculo, ao destacar a individualidade como a "soma das relações sociais da vida do sujeito e não como entidade submissa ao social" (BAKHTIN apud SOBRAL, 2005b, p. 104-105). Este mesmo autor destaca ainda que Bakhtin: 
vê o sujeito no âmbito de uma arquitetônica ${ }^{2}$ em que os diferentes elementos que constituem sua fluida e situada identidade estão em permanente tensão, em constante articulação dialógica, em permanente negociação de formas de composição, em vez de unidos mecanicamente (BAKHTIN apud SOBRAL, 2005b, p. 104-105).

Lüdke e Boing (2004, p. 1.168-1.169), ao apontarem a fragilidade da identidade profissional docente, destacam o fato de esta não ser considerada "tão específica" aos olhos da sociedade, que aceita com tranqüilidade o fato de que pessoas com diferentes qualificaçōes exerçam a docência. $\mathrm{O}$ tratamento social que observamos em relação ao professor acata com relativa tranqüilidade o fato de que profissionais de diferentes áreas atuem como docentes, em uma perspectiva de entendimento de que o domínio do conteúdo do saber é suficiente para que se dê o ensino, desconsiderando a existência de uma especificidade cientificamente definida para que se constituam processos de ensino que efetivamente se consolidem em aprendizagem.

$\mathrm{Na}$ Educação Especial, essa questão se agrava e a definição acerca de quem é o profissional responsável pela educação dos indivíduos que apresentam diferenças biológicas expressivas tem sido bastante controversa. Nas discussões acerca da Identidade Profissional do Professor e de sua Profissionalização, a temática da diversidade ainda aparece como um dado pontual, registrando-se uma tendência a tratar os professores que atuam com pessoas com deficiência como especialistas, profissionais com peculiaridades que os isolam das discussões gerais realizadas pelos professores das instituições de Ensino Regular.

Estabelece-se, assim, uma categorização desses profissionais como professores $d a$ Educação Especial, responsabilizados por toda e qualquer discussão que envolva a educação de crianças que venham a ser consideradas no ambiente escolar como alunos com necessidades educativas especiais, na contramão do movimento histórico que vivenciamos na atualidade, em que as políticas públicas de educação se direcionam para a construção de uma Educação Inclusiva.

A pesquisa que aqui desenvolvemos foi realizada com sete professoras ${ }^{3}$ vinculadas ao setor de Educação Especial da rede estadual de ensino de Roraima e que atuam em serviços de apoio pedagógico especializado às escolas de Ensino Regular que têm alunos com deficiência matriculados em suas turmas, sendo consideradas profissionais de referência em suas respectivas áreas. 


\section{A PERSPECTIVA HISTÓRICO-CULTURAL COMO FUNDAMENTO TEÓRICO-METODOLÓGICO PARA COMPREENSÃO DA CONSTRUÇÃO DA IDENTIDADE DOCENTE}

Considerando que o processo de constituição da profissionalidade docente e as práticas do cotidiano escolar estão inseridos em um contexto histórico, social e cultural e também que a concepção de que os homens são seres constituídos nas relações sociais em determinado contexto, em que dialeticamente se constituem ao tempo em que alteram essa mesma realidade, assumimos como perspectiva de reflexão teóricometodológica, a perspectiva histórico-cultural, tomando como autores fundamentais para essas reflexões teóricas Bakhtin e sua teoria enunciativa da linguagem e Vigotski com a teoria da construção social do conhecimento. Esses autores têm sido alvo de um conjunto expressivo de pesquisadores brasileiros, dentre os quais se destacam Amorim (2004), Freitas (2003) e Kramer (2003), que desenvolvem um esforço de estabelecer instrumentos e práticas de pesquisa consistentes e articulados com o referencial teórico que orienta suas açôes, e que nos subsidiaram na definição de um processo de pesquisa que articulasse o referencial teórico aos procedimentos metodológicos de inserção no campo.

Neste sentido, a partir do referencial histórico-cultural, orientamos não só nossos procedimentos de pesquisa, como as análises de resultados encontrados, entendendo que a presença do pesquisador em campo não só possibilita estabelecer determinada leitura da realidade, como também altera essa realidade, no momento mesmo em que cria espaços para a reflexão e evidenciação dos elementos que direcionam as práticas sociais daquele contexto

Conforme nos aponta Freitas (1998, p. 31), Bakhtin e Vigotski, "partindo de uma mesma fundamentação dialética, se encontram na centralidade que conferem à linguagem, na mediação semiótica, na constituição da consciência”. São autores que desenvolvem seus estudos na perspectiva posta pelo materialismo histórico-dialético de que "o homem só é indivíduo, ou melhor, só se constitui como indivíduo porque é social e histórico" (GONÇALVES, 2002, p. 44), ou seja, os indivíduos só existem no contexto da sociedade e trazem em seus discursos também o conjunto da sociedade.

Para esses autores, a pesquisa em Ciências Humanas, ao ser desenvolvida com seres humanos, tomando por base seus discursos, precisa considerar o fato de que o nosso "falante" não é o primeiro falante, um "Adão bíblico", como se refere Bakhtin, mas um sujeito que constrói seus enunciados ${ }^{4}$ a partir de outros tantos enunciados antecedentes, com os quais estabelece relações. Além disso, todo enunciado é sempre produto da interação entre falantes, tem um endereçamento, um autor e um destinatário.

Em nossa pesquisa, adotamos como instrumento de levantamento de dados entrevistas coletivas que favorecem o estabelecimento de diálogos e inter-relações entre 
as participantes. No processo de análise, procuramos compreender a forma como se deu a construção da Identidade Profissional dessas professoras, fiéis à perspectiva bakhtiniana de compreensão, aqui entendida como um empenho em "ver e compreender o outro e o seu mundo, outro sujeito". Para Bakhtin, (2003, p. 316), "na explicação existe apenas uma consciência, um sujeito; na compreensão, duas consciências, dois sujeitos".

Neste movimento de reflexão acerca das histórias de vida dessas professoras, de sua formação pessoal e profissional, buscamos identificar pontos onde os discursos se mostravam reincidentes, onde se davam suas intersecçóes, não com a expectativa de uma pretensa identificação de "verdades" ou "contradiçōes", mas buscando compreender os processos vivenciados por essas professoras em seu contexto de atuação profissional e como estes foram por elas retratados. Destas reincidências e intersecções emergiram três categorias a partir das quais direcionamos nossos processos de análise:

1. Fatores que direcionaram a escolha profissional;

2. Relações com a diferença;

3. Aspectos que envolvem a profissionalidade docente.

\section{OS FATORES QUE DIRECIONARAM A ESCOLHA PROFISSIONAL}

A forma como as profissionais fizeram sua entrada na carreira docente, os fatores que direcionaram essa decisão e como, no amplo espectro de possibilidades da área da Educação, foram se aproximando da Educação Especial foram elementos que emergiram como relevantes ao longo das entrevistas.

A situação posta pelo contexto sócio-econômico e político surge nos discursos como determinante do encaminhamento profissional adotado por algumas de nossas entrevistadas. Nem sempre a inserção na área é caracterizada por elas como uma "opção", gerando um movimento que optamos por denominar de "acaso".

Esse "acaso", declarado em vários discursos como um fator que levou ao ingresso na área, termina confrontado por um componente decisório que se manifesta na permanência e no envolvimento que posteriormente, ao longo da carreira profissional, se desenvolve.

Dessa forma, o que entendemos estar na base dessas decisões é a volição, como concebido por Vigotski (2001): a expressão da vontade, do desejo como força motivadora para a ação consciente, auto-regulada. Essa perspectiva se afina, ainda, à idéia do ato como uma ação material de cada homem situado historicamente, conforme apresentado por Bakhtin em seu texto Filosofia do Ato, quando aponta que toda a decisão ética do indivíduo é tomada na concretude de sua vida, a partir das ocorrências materiais que a direcionam. Neste sentido, "o ato realmente realizado em seu todo indivisível é mais do que racional: ele é responsável” (BAKHTIN, 1993, p. 47). Em essência: 
Não é o conteúdo de uma obrigação que me obriga, mas minha assinatura sob ela; o fato de que uma vez eu reconheci ou subscrevi um dado reconhecimento. E o que me compeliu a assinar no momento de assinar não foi o conteúdo de um dado ato realizado ou ação. Esse conteúdo não poderia, por si, isoladamente, ter me obrigado a realizar o ato ou ação - assinarreconhecer - mas apenas em correlação com minha decisão de assumir uma obrigação realizando o ato de subscrever-reconhecendo. E nesse ato realizado o aspecto do conteúdo não foi senão um momento constituinte, e o que decidiu o assunto foi o reconhecimento ou afirmação - a ação responsável - que tinha sido realmente realizada anteriormente (BAKHTIN, 1993, p. 56-57).

Outro aspecto que se destacou foi a forte presença do sentimento religioso, atribuindo um caráter missionário ao trabalho pedagógico, e que se apresentou, com maior ou menor grau, na fala de todas as participantes.

Lüdke e Boing (2004, p. 1173) destacam o fato de que, anteriormente, o "modelo de professor era o religioso, envolvendo a docência numa aura de vocação e sacerdócio, mesmo em se tratando de professores leigos". Esse ethos religioso (TARDIFF; LESSARD, 2005) que já atravessa a concepção do "ser professor" se soma às posturas religiosas filantrópicas e assistencialistas que atravessam a concepção de deficiência em nossa sociedade.

Em nossa observação, a incorporação de um discurso que atribui caráter missionário à própria profissão do magistério como um todo, ${ }^{5}$ atinge de maneira ainda mais intensa os professores que atuam na Educação Especial, gerando uma imagem profissional tanto no conjunto da sociedade, quanto na leitura dos demais colegas de profissão, que desconsidera a natureza profissional de sua atividade, e fortalece a perspectiva altruísta, amorosa e messiânica de sua atuação. É o professor agraciado com uma missão divina, com o poder de redimir indivíduos demarcados com um estigma de natureza biológica e, conseqüentemente, a si próprios.

A presença de pessoas com deficiência na familia como um fator que possa ter direcionado ou tido influência na entrada dessas profissionais na área da Educação Especial é apontada por duas de nossas entrevistadas, que irão direcionar-se, pessoal e profissionalmente, no sentido não só de compreender o processo ocorrido em sua família, por meio de uma formação acadêmica, mas também aparentam o desejo de "resgatar" socialmente o que entendem não ter sido adequadamente realizado em seu passado, direcionando suas carreiras para uma profissão em que atuam com outras crianças em condição semelhante.

Um último fator que determina a entrada na área, apontado por uma de nossas entrevistadas, permeou também outros discursos, principalmente quando nos reportamos aos elementos que direcionam a permanência na profissão: o desafio que envolve o enfrentamento aos limites e dificuldades da atuação profissional do docente que tem por opção a educação de pessoas com deficiência. 
Vigotski (2006), ao discutir a teoria dinâmica do caráter, destaca que nela dois postulados fundamentais se revelam, manifestando sua interligação como elementos em continuação dinâmica: "a explicação para a orientação psicológica ao futuro e o princípio de compensação no desenvolvimento da psique". Em seu entendimento, "a existência de obstáculos cria o 'objetivo' para os atos psíquicos, ou seja, introduz no desenvolvimento da psique a perspectiva do futuro" (p. 284-285).

Em um esforço de aproximação teórica, identificamos aí a realização de uma trajetória dessa natureza e que, aparentemente, não só encaminhou a opção inicial da atuação profissional, como assegurou a permanência ativa e compromissada ao longo de toda uma vida laboral.

Consideramos que a construção da Identificação dessas profissionais com sua área de atuação se inicia no ato de sua aceitação do caminho profissional que lhes foi sendo apresentado, mesmo quando essa escolha não parte de uma identificação previamente entendida como vocacional. Mesmo nos casos em que o peso maior da escolha é atribuído ao acaso ou às condições do contexto de formação, que em determinados períodos só apresentava opçōes de formação nesta área, todas atingiram um grau de identificação com a chamada Educação Especial que parece favorecer o envolvimento com suas responsabilidades profissionais.

\section{AS RELAÇÕES COM A DIFERENÇA}

As histórias de vida das professoras com as quais dialogamos, no tocante à maneira como foram se apercebendo das diferenças e dos diferentes valores socialmente atribuídos a elas, nos ofereceram um rico painel de como essas relações com a diferença vêm se dando em nossa sociedade. Da total negação da existência das diferenças ao convívio cotidiano com o preconceito com que são tratados os estigmatizados, várias experiências foram relatadas.

E como essas relações com a diferença se refletem na constituição da identidade profissional dessas professoras, profissionais que assumiram como campo de trabalho preferencial crianças, adolescentes e adultos com deficiências? Identificamos três perspectivas que categorizamos como perfis identitários de relação com a diferença. Cumpre destacar que não pretendemos, com a categorização dessas três perspectivas, engessar os indivíduos, enquadrando-os em rótulos pré-definidos, mas apenas aprofundar um olhar sobre posicionamentos que os sujeitos assumem em suas vidas.

Identificamos a existência de profissionais que atuam na perspectiva de correção do defeito, gerando práticas educacionais focadas na construção de estratégias de superação dos limites associados ao defeito, de forma que o indivíduo possa vir a ser inserido na sociedade tida como "normal". É a diferença posta no "Outro", e não a diferença como base do ser humano. 
Um segundo grupo entre os nossos entrevistados manifestou um perfil identitário que, nas relações com a diferença, parte da compreensão dessa diferença como um elemento presente entre os seres humanos a ser assumido como um dos componentes da vida social e cultural, respeitados os limites e potencialidades de todos.

Um terceiro perfil que identificamos como emergente nos discursos de nossas entrevistadas foi a da conscientização, que entende a diferença como elemento essencial da natureza humana, e que projeta a concretização do Múltiplo, como valor social, do múltiplo como "o único universal possível” (MARQUES; MARQUES, 2003, p. 234) ou de privilégio à multiplicidade, conforme nos trazem Corazza e Silva (2003, p. 13):

Privilegiar a multiplicidade em vez da diversidade. Fazer proliferar o sinal da multiplicação. A diversidade é estática, é um estado, é estéril. A multiplicidade é uma máquina de produzir diferenças - diferenças que são irredutíveis à identidade. A diversidade limita-se ao existente. A multiplicidade estende e multiplica, prolifera, dissemina. A diversidade é um dado - da natureza ou da cultura. A multiplicidade é um movimento. A diversidade reafirma o idêntico.

A multiplicidade estimula a diferença que se recusa a se fundir com o idêntico.

São alguns dos discursos sociais acerca da diferença que se reproduzem e se manifestam entre nossas professoras, mas, longe de pretender construir generalizações a partir de um conjunto restrito de histórias de vida, pretendemos que, com a compreensão dessas diferentes perspectivas de formação identitária, possamos refletir positivamente acerca de mecanismos de relação com a diferença, construídos por cada um de nós em nossas esferas de atuação.

\section{OS ASPECTOS QUE ENVOLVEM A PROFISSIONALIDADE DOCENTE}

Ao longo dos diálogos que fomos construindo no desafio de compreender o processo de constituição identitária do professor considerado referência em Educação Especial, nesse momento histórico em que a tônica dos discursos se foca na Inclusão Educacional, parte expressiva dos enunciados se centraram nas questôes que envolvem a profissionalização docente e a profissionalização do ensino como um todo.

Essa concepção da profissionalização dá-se num contexto em que a idéia predominante é a da docência como profissão que exige uma base de formação e uma condição de atuação profissional que perpassa desde as questões de remuneração e organização do tempo-espaço escolar, até o reconhecimento e valorização social da profissão. Afinados com o pensamento de Alarcão (1996), Brzezinski (2002), Lüdke e Boing (2004), Ramalho, Nuñez e Gauthier (2003) apontam que essa profissionalização encontra-se em construção ao mesmo tempo em que se verifica a proletarização da docência, fato que os relatos e observaçôes das professoras com as quais dialogamos acabam por referendar. 
O olhar sobre a constituição identitária com base nas vivências profissionais parte de um entendimento de que estamos buscando compreender um "fenômeno psicológico não só em relação ao seu passado, mas também ao seu futuro", no esforço de assumir a exigência dialética que nos aponta Vigotski (2006, p. 283) : "de conceber os fenômenos em seu permanente movimento, de descobrir nos fenômenos suas tendências, seu futuro, definido por seu presente".

Alguns temas foram reincidentemente tocados pelas professoras ao longo de nossas entrevistas. Para facilitar nosso processo de reflexão e análise, foram agrupados em subcategorias. São elas: os processos formativos; o momento do ingresso na carreira docente; a organização docente e suas conseqüências para o cotidiano profissional; a realização profissional ou impotência diante de seu trabalho; reflexões acerca do professor que forma o professor e as questóes que envolvem o compromisso ou a paixão pela profissão.

Optamos por tomar os processos formativos como elemento de reflexão, por entender, como Placco (2006, p. 45), que "aprender a ensinar confunde-se com o próprio desenvolvimento da subjetividade". ${ }^{6}$

A necessidade interna de formação no encontro com as dificuldades de seu cotidiano profissional e a identificação da importância do respaldo teórico em suas práticas movimenta essas professoras. Nem todas passaram por formação anterior à inserção na carreira docente. Elas, então, partem para um esforço individual de compensação dos limites estabelecidos pela baixa qualificação teórica prévia, de maneira assistemática, nem sempre apoiadas pelos sistemas educacionais ao qual estão profissionalmente vinculadas.

De maneira geral, todas manifestam interesse em dar continuidade à sua formação. Questionam, no entanto, se essa formação vai ser direcionada no sentido de aprofundar uma especialização em determinada área, firmando uma identidade profissional com o específico, com o especial, ou se essa formação projeta um sentido de ampliação de horizontes, de abertura de um leque de opções pedagógicas. Neste caso, verificamos posições antagônicas entre as participantes, mas que foram sendo revistas e rediscutidas ao longo de nossos encontros.

Há as professoras que se identificam como especialistas, se colocam nesse lugar, sem interesse em alterar sua posição, por entender que há um longo percurso de construção de saberes a ser elaborado acerca de processos de aprendizagem de pessoas que apresentam diferenças biológicas expressivas, como, por exemplo, no caso do ensino de surdos. Então, optam por seguir uma trajetória de afunilamento da especificidade de sua formação.

Há também aquelas que se identificam prioritariamente como professoras, portanto entendendo ser sujeitas a encontrarem-se com sujeitos em condições biológicas variadas, não pretendendo nenhuma superespecialização, mas sim a construção de uma trajetória 
de identificação com a educação em geral, trazendo, para esta, um olhar que amplie o leque das possibilidades humanas, que considere a multiplicidade de possibilidades dos indivíduos.

Interessante destacar que o foco é sempre colocado em formações que seriam realizadas por profissionais externos à sua rotina. Há que se questionar, no entanto, até que ponto isso não reflete o discurso circulante que atribui ao professor a incapacidade de desenvolvimento em sua própria profissão. A ansiedade pelo alcance de resultados considerados adequados acaba sendo deslocada para fora dos indivíduos, como se o domínio teórico e a palavra de outros especialistas, por si, pudesse trazer a solução às angústias geradas pelo amplo espectro de dificuldades vivenciadas no cotidiano.

Entendemos que, nessa busca externa de soluções, perde-se também o foco sobre o rico campo de reflexão, de análise e de estudo dos casos que compõem de maneira concreta o campo de ação do cotidiano docente.

Nas histórias de vida contadas pelas professoras, o momento do ingresso na carreira docente foi destacado por todas. A primeira experiência com a docência em Educação Especial, que em alguns casos representa também um dos primeiros contatos diretos com a deficiência, é relatado como um momento impactante, em que sentimentos de medo, angústia e ímpeto de desistência se misturam. Mas a força desse incômodo parece ser o que, de acordo com Vigotski (2004, p. 461), lhes dá maior impulso de superação. No entendimento desse autor, "quanto mais forte é o incômodo que dá o primeiro impulso ao movimento da alma, tanto mais forte é o próprio movimento"; nesse sentido, "a educação e a criação são sempre trágicas, porque partem do 'incômodo' e do mal-estar, da desarmonia”.

Os relatos apontam a importância de profissionais com mais longa experiência profissional e de vida que, com uma noção da educação como processo, auxiliam o processo de ingresso dos profissionais iniciantes.

Há relatos acerca do contato com práticas que as participantes de nossa pesquisa consideram inadequadas, com discursos que parecem desconectados de um sentido pedagógico sólido, mas impressiona o poder do discurso positivo no processo de entrada desses profissionais na área, a intervenção do exemplo positivo em sua formação identitária.

Como foi possível verificar desde o início de nossa entrada no campo de pesquisa, a atual organização do trabalho docente interfere profundamente na constituição da identidade profissional dos professores. Afeta desde a questão de formação e aperfeiçoamento da ação docente dos profissionais, na medida em que a distribuição dos tempos escolares limita as condiçôes de análise, planejamento e interlocução dos professores com seus pares ou com outros profissionais. Compromete o sentido de valor dos profissionais, na medida em que estes, não dispondo dos meios de aperfeiçoamento 
técnico, nem dos recursos materiais necessários à execução de seu trabalho, atuam sob tensão constante, com resultados aquém do que almejam.

Em que pesem as consequiências decorrentes da inadequação do tempo escolar às necessidades pedagógicas de alunos e professores e da inexistência de condições materiais minimamente desejáveis ao exercício profissional, o fator apontado por todas como o mais impactante na constituição de suas identidades está localizado nas relaçôes de poder estabelecidas em seu ambiente de trabalho. A distribuição de papéis no sistema educacional, em que a um grupo de profissionais é relegada a tarefa de executores de ações sobre as quais eles não detêm o controle do planejamento ou da elaboração teórica e conceitual, acarreta danos graves à manutenção de vínculos desses professores com sua atividade cotidiana, como iremos evidenciar na discussão acerca da realização e/ou do sentimento de impotência manifestado por esses profissionais.

Outro aspecto da organização do trabalho docente demarcado em nossas entrevistas foi a dicotomização entre o sistema considerado como Regular e a condição de modalidade "à parte" representada pela Educação Especial, que coloca não só as crianças com deficiência como "especiais", mas considera os próprios profissionais que atuam com essas crianças como "especiais". Essa separação em alguns momentos é assumida por esses profissionais, que se posicionam também nesse lugar do "especial"; em outros é rejeitada, com um discurso que almeja chegar a uma organização em que os profissionais considerados referência na educação de pessoas com deficiências, os especialistas, estejam naturalmente inseridos no ambiente escolar e nos espaços de organização da educação básica, em uma posição de efetiva Inclusão ${ }^{7}$ de discentes e docentes, e não apenas de sua inserção no sistema.

Elemento que entendemos ser fundamental no exercício de uma profissão, a realização trazida pela concretização de seu trabalho é apontada como fator importantíssimo para a permanência na área, se sobrepondo inclusive a outras questóes, como o retorno financeiro ou o status de inferioridade atribuído ao professor em nosso país. São retornos que realimentam no profissional o ímpeto de prosseguir em seu trabalho e que vão colaborar na composição de uma Identidade Profissional positiva.

As professoras vão dar destaque também à importância do reconhecimento social, de como a percepção positiva de famílias ou de colegas acerca de sua atuação se mostra relevante para a sua realização profissional. Na ótica bakhtiniana, é o agir situado e avaliativo do sujeito no mundo, o valor aqui entendido como "valor para sujeitos, entre sujeitos, numa dada situação" (SOBRAL, 2005a, p. 22).

Esses momentos de realização profissional se mesclam, ao longo da carreira docente, com momentos em que o profissional se vê impotente diante de situações em que não detém o controle e acompanhamento dos resultados de seu trabalho. Em alguns casos, entendendo como fase de transição em seu percurso profissional, em outros analisando inclusive a possibilidade de abandono da carreira. 
O processo de tornarem-se referências em áreas específicas da Educação Especial, com conhecimentos que as colocam como especialistas em suas esferas de atuação, tem possibilitado a essas profissionais se colocarem também como "formadoras" de professores. Essas ações se dão quando atuam seja como palestrantes em escolas de educação básica, ensino superior ou eventos como congressos e seminários; seja como docentes de cursos de curta duração (na chamada formação continuada) ou disciplinas específicas da graduação em pedagogia ou licenciaturas.

Essas experiências trouxeram à tona uma discussão presente no cotidiano da Educação Superior: quem forma o professor? Que formação tem esse profissional hoje? Que estrutura de formação está sendo oferecida na graduação aos professores para possibilitar-lhes romper com os padrôes de cultura escolar hoje existentes?

É no jogo de forças entre uma Identidade Profissional que o posiciona como especialista - o professor referência de quem se espera que surjam as respostas às angústias e dificuldades dos professores no cotidiano do ensino regular - e uma Identidade de profissional também em processo formativo, com uma trajetória de descobertas a realizar, que alguns elementos desejáveis na constituição do professor formador foram apontados: o domínio técnico-teórico da área; uma sólida formação acerca dos processos de desenvolvimento e de aprendizagem do homem como ser social; a clareza política do papel social da educação; e um sólido sentido ético que perpasse todos esses campos, articulando-os coerentemente.

O debate entre questôes que envolvem o compromisso ou a paixão pela área como elementos de permanência na profissão e os vários sentidos atribuídos pelos docentes à educação de pessoas com deficiências apresentaram diferentes perspectivas de envolvimento do profissional com sua atividade profissional, mas evidenciaram, em sua essência, a responsabilidade dessas com o mundo que as circunda e com os demais seres humanos. $\mathrm{Na}$ ótica bakhtiniana:

Um ato ou ação responsável é precisamente aquele ato realizado sob a base de um reconhecimento da minha obrigatória unicidade. É essa afirmação do meu não-álibi no Ser que constitui a base da minha vida sendo tanto real e necessariamente dada como também sendo real e necessariamente projetada como algo-ainda-por-ser-alcançado. É apenas o meu não-álibi no Ser que transforma uma possibilidade vazia em um ato ou ação responsável e real. Este é o fato vivo de um ato ou ação primordial que produz pela primeira vez o ato responsavelmente realizado - produz seu peso real, sua compulsoriedade; é a fundação da minha vida como ação-realizar, porque, para ser na vida, ser realmente, é agir, é ser nãoindiferente com relação ao todo único (BAKHTIN, 1993, p. 60).

Essa não-indiferença vai estender-se a outros campos da atuação profissional dessas professoras, trazendo uma postura particularmente compromissada nos momentos em que essa atuação se constitui como formação de outros professores. No entanto, essa 
visceralidade manifestada por esses profissionais se mostra negativamente surpreendida, em vários momentos de nossos diálogos, com a postura apática, desencantada e, por vezes, não comprometida de profissionais com os quais as professoras interagem em seu cotidiano, quando se dão conta de que o que consideram como postura natural do profissional é ignorado por alguns colegas.

Referem-se a profissionais aparentemente não tocados pelo sentido de sua responsabilidade como Ser. Bakhtin (1993, p. 61) se refere a esses como Seres desencarnados na sua responsabilidade, que têm "o pensamento não encarnado, a ação não-encarnada, a vida fortuita não-encarnada como uma possibilidade vazia”. São professores afetados pelo desencanto ou pelo alheamento em relação a seu trabalho, o que os coloca em "uma vida vivida na base tácita do meu não-álibi no Ser, cai no Ser indiferente que não está enraizado em nada".

No diálogo com essas profissionais que assumiram como base constitutiva de suas Identidades que "viver dentro de si mesmo não significa viver para si, mas significa ser um participante responsável dentro de si”; que afirmam com sua prática o "não-álibi real e compulsório no Ser" (BAKHTIN, 1993, p. 67), emergiram discussões que, extrapolando o sentido da Identidade Profissional de cada um individualmente, foram tocar na questão do espaço ocupado pela Educação Especial nesses tempos em que cada dia mais se fortalece o debate em torno da Educação Inclusiva, tema que demanda um aprofundamento que extrapola os limites deste trabalho, mas ao qual não pudemos deixar de tocar em nossas consideraçôes finais.

\section{PARA NÃO CONCLUIR}

O objetivo central deste trabalho foi compreender a forma como professoras que atuam com a educação de pessoas com deficiência constituem sua Identidade Profissional, neste momento em que o foco das discussões está posto na perspectiva da Inclusão de todas as crianças no sistema educacional regular.

Nas entrevistas, pudemos evidenciar a forma como as condições do contexto são efetivamente demarcadoras de nossas Identidades, percebendo, porém, como cada professora participante da pesquisa aponta marcas das formas próprias através das quais retratou as condições do contexto de suas vidas.

Dos elementos que interferem na constituição identitária dessas professoras, destacamos a crise que envolve a Profissionalidade Docente, em que a forma como o Trabalho Docente encontra-se organizado limita e, em alguns casos, impede condições de formação que levem à formulação e reformulação de práticas no interior das escolas. Trata-se, no entanto, de uma condição comum ao modo como o sistema educacional se encontra estruturado atualmente. 
A forma de estabelecer relações com a diferença, posicionando-se na perspectiva da correção ou da compensação do defeito; ou ainda com um foco na conscientização acerca da contribuição da diferença na vida social, também define de maneira expressiva o agir profissional de cada docente. É de seu posicionamento apontando a diferença como característica do "outro", ou de "todos", que se demarca uma das bases do perfil identitário desses docentes.

Um elemento transversal a todo o nosso processo de pesquisa foi a reflexão acerca do lugar ocupado pela chamada Educação Especial e pelos profissionais que nela atuam hoje. Qual o locus de atuação dos professores que direcionaram suas formações para a educação de pessoas com deficiências, neste momento em que os alunos com deficiência estão sendo inseridos em turmas de ensino regular? Que identidade esses profissionais assumirão no exercício de sua atividade profissional? Atuarão como especialistas nos serviços de apoio, planejando e difundindo junto aos professores do ensino regular estratégias pedagógicas para a educação de pessoas com deficiências - caso da maior parte de nossas entrevistadas - ou atuarão como professores generalistas no interior das escolas, vivenciando o cotidiano pedagógico com suas dúvidas e busca de soluções partilhadas por todos os professores?

Em essência, essa polarização quanto aos possíveis locus de atuação traz em si a dicotomização entre Ensino Regular e Educação Especial e a ótica de uma Identidade Profissional que conserva o sentido do professor especialista em áreas de deficiência, a quem compete dar resposta às dificuldades vivenciadas pelos professores atuantes em turmas de ensino regular, em detrimento da formação de professores generalistas, cuja formação possibilite estabelecer estratégias pedagógicas a partir das diferentes condiçōes que se apresentem em seu cotidiano profissional, construindo e reconstruindo seus saberes e práticas de maneira articulada às demandas de sua sala de aula real.

Em nosso entendimento, no entanto, nesta construção que vimos fazendo coletivamente, com avanços e retrocessos diários, destacamos a importância da tensão gerada pelos conflitos e contradições vivenciados no interior dos sistemas educacionais como elemento que contribui na reformulação de parâmetros, sinalizando caminhos de superação que nos autorizam a projetar um tempo em que pessoas em processo de formação escolar sejam vistas em sua totalidade, a partir de suas necessidades e potencialidades. Tempo em que os professores poderão desenvolver sua docência de maneira responsiva e responsável, como elementos éticos de sua condição de docentes e de seres humanos. Tempo em que as forças centrífugas, carnavalizadoras e transgressoras de discursos monológicos e autoritários venham a emergir, possibilitando que o Múltiplo se constitua a base da construção de uma sociedade em que se articulem ativamente as várias vozes que constituem o humano em nós. 


\section{Notas}

1. Expressão incorporada inclusive na Política Nacional de Educação Especial recentemente sancionada pelo MEC (BRASIL, 2008).

2. Arquitetônica para Bakhtin (2003, p. XVII) é o "ponto de encontro e de interação entre material, forma e conteúdo".

3. Todas são profissionais do sexo feminino, mantendo um perfil de gênero já apontado por autores que registram a feminização do magistério como Fontana (2005), Assunção (1996) e Gomes (1995).

4. Tomando por base a Teoria da Enunciação de Bakhtin (2006), pode-se afirmar que enunciado é a materialização da língua. Enunciados apresentam três dimensões indissoluvelmente ligadas: são concretos e singulares, ligados às condições sociais em que são produzidos na dinâmica das relaçóes sociais que, por sua vez, estão sempre ligadas às estruturas sociais; refletem essas condiçôes específicas e o objeto de cada uma das esferas da práxis humana, no seu conteúdo temático, no seu estilo verbal, ou seja, a seleção dos recursos léxicos, fraseológicos e gramaticais da língua e na sua composição ou estruturação.

5. Discurso este amplamente utilizado na justificativa e no incentivo à tolerância da categoria profissional do magistério diante da precarização de sua condição docente, em especial nos momentos em que movimentos organizados pela melhoria das condiçóes de trabalho e salário dos professores vêm à tona.

6. Não estamos utilizando o termo subjetividade como "intercambiável" ou substitutivo de identidade. Nos apropriamos aqui do entendimento de Woodward (2005, p. 55) de que a subjetividade "sugere a compreensão que temos sobre o nosso eu. O termo envolve os pensamentos e as emoções conscientes e inconscientes que constituem nossas concepções sobre 'quem somos nós'; a subjetividade envolve nossos sentimentos e pensamentos mais pessoais", já a identidade é constituída pelas "posiçôes que assumimos e com as quais nos identificamos" dentro do "contexto social no qual a linguagem e a cultura dão significado à experiência que temos de nós mesmos".

7. Entendemos que a Inclusão só se efetive realmente na medida em que sejam oferecidas condições reais para a educação de todas as crianças, com garantia de condições de acesso e permanência no sistema educacional.

\section{Referências}

ALARCÃO, Isabel (Org.). Formação reflexiva de professores: estratégias de supervisão. Porto: Porto Editora, 1996.

AMORIM, Marília. O pesquisador e seu outro: Bakhtin nas ciências humanas. São Paulo: Musa Editora, 2004.

ASSUNÇÃO, Maria Madalena S. de. Magistério primário e cotidiano escolar. Campinas: Autores Associados, 1996.

BAKHTIN, Mikhail. Toward a Philosophy or the Act. Trad.: (para uso didático e acadêmico) Carlos Alberto Faraco e Cristóvão Tezza. Austin: University of Texas Press, 1993.

Estética da criação verbal. Trad.: Paulo Bezerra. São Paulo: Martins Fontes, 2003.

(Volochinov). Marxismo e filosofia da linguagem. Trad.: Michel Laud e Yara Frateschi

Vieira. São Paulo: Hucitec, 2006. 
BRASIL. Política Nacional de Educação Especial. Brasília: MEC, 2008.

BRZEZINSKI, Iria. Profissão professor: identidade e profissionalização docente. Brasília: Plano, 2002.

BUENO, Belmira Oliveira. O método autobiográfico e os estudos com histórias de vida de professores: a questão da subjetividade. Revista Educação e Pesquisa, São Paulo, v. 28, n. 1, p. 11-30, jan./jun. 2002. CORAZZA, Sandra; SILVA, Tomaz Tadeu. Composiçōes. Belo Horizonte: Autêntica, 2003.

FONTANA, Roseli A. Cação. Como nos tornamos professoras?3. ed. Belo Horizonte: Autêntica, 2005. FREITAS, Maria Teresa de Assunção (Org.). Narrativas de professores: pesquisando leitura e escrita numa perspectiva sócio-histórica. Rio de Janeiro: Ravil, 1998.

. Vigotski e Bakhtin, psicologia e educação: um intertexto. São Paulo: Ática, 2003.

GOMES, Nilma. A mulher negra que vi de perto. Belo Horizonte: Mazza Edições, 1995.

GONÇALVES, Maria da Graça Marquina. A Psicologia como ciência do sujeito e da subjetividade: a historicidade como noção básica. In: BOCK, Ana Mercês Bahia; GONÇALVES, Maria da Graça Marquina; FURTADO, Odair (Orgs.). Psicologia sócio-histórica: uma perspectiva crítica em Psicologia. São Paulo: Cortez, 2002. p. 37-52.

KRAMER, Sônia. Entrevistas coletivas: uma alternativa para lidar com a diversidade, hierarquia e poder na pesquisa em ciências humanas. In: FREITAS, Maria Teresa; SOUZA, Solange Jobim; KRAMER, Sônia (Orgs.). Ciências Humanas e pesquisa: leituras de Mikhail Bakhtin. São Paulo: Cortez, 2003. p. 57-76. LÜDKE, Menga; BOING, Luiz Alberto. Caminhos da profissão e da profissionalidade docente. Educação e Sociedade, Campinas, v. 25, n. 89, p. 1.159-1.180, 2004.

MARQUES, Carlos Alberto; MARQUES, Luciana Pacheco. Do universal ao múltiplo: os caminhos da inclusão. In: LISITA, Verbena Moreira S. de S.; SOUSA, Luciana Freire E. C. P. (Orgs.). Políticas educacionais, práticas escolares e alternativas de inclusão escolar. Rio de Janeiro: DP\&A, 2003. p. 223-239. PLACCO, Vera Maria Nigro de Souza; SOUZA, Vera Lúcia Trevisan. (Orgs.). Aprendizagem do adulto professor. São Paulo: Loyola, 2006.

RAMALHO, Betania Leite; NUÑEZ, Isauro Beltran; GAUTHIER, Clermont. Formar o professor, profissionalizar o ensino: perspectivas e desafios. Porto Alegre: Sulina, 2003.

SOBRAL, Adail. Ato/atividade e evento. In: BRAIT, Beth. Bakhtin: conceitos-chave. São Paulo: Contexto, 2005a. p. 11-35.

. Ético e estético: Na vida, na arte e na pesquisa em ciências humanas. In: BRAIT, Beth. Bakhtin: conceitos-chave. São Paulo: Contexto, 2005b. p. 103-122.

TARDIF, Maurice; LESSARD, Claude. O trabalho docente: elementos para uma teoria da docência como profissão de interações humanas. Petrópolis: Vozes, 2005.

VIGOTSKI, Liev Semionovitch. A construção do pensamento e da linguagem. Trad.: Paulo Bezerra. São Paulo: Martins Fontes, 2001.

Psicologia pedagógica. Trad.: Paulo Bezerra. São Paulo: Martins Fontes, 2004.

Sobre a questão da dinâmica do caráter infantil. Trad.: Zoia Prestes. Linhas Críticas, Brasília, v. 12, n. 23, p. 279-291, jul./dez. 2006.

WOODWARD, Kathryn. Identidade e diferença: uma introdução teórica e conceitual. In: SILVA, Tomaz Tadeu (Org.). Identidade e diferença: a perspectiva dos estudos culturais. 4. ed. Petrópolis: Vozes, 2005. 


\section{Special education in times of inclusive education: the identity of the teacher in question Abstract}

We present a research carried out within a Master in Education Program in which we try to understand the way through which teachers who work in Special Education constitute their Professional Identity in this moment when discussions point out towards Inclusive Education. We identified the factors that contributed in the life histories with which these teachers have built their professional identity, so that they can position themselves as Special Education teachers. We took as theoretical reference the historicalcultural perspective, especially the studies of Baktin and Vygotsky. In the collective interviews carried out with a group of seven teachers of public schools of Roraima, we studied the process of identity constitution of those teachers considering their personal, academic and professional life history, identifying the marking influence of the present structure of organization of teacher work in their professional profiles. Keywords: Special education. Teacher training. Inclusion. Teacher identity. Teacher professional skills.

\section{L'éducation spéciale en temps de l'éducation inclusive : l'identité du professeur en question} Résumé

Nous présentons une recherche réalisée au long d'un cours de la Maîtrise en Éducation, dans lequel nous avons cherché à comprendre la forme par laquelle les maîtres travaillent avec des personnes porteurs de déficiences, considérés socialement comme professeurs d'Éducation Spéciale, constituent leur Identité Professionnelle en ce moment où les discussions se dirigent vers l'Éducation Inclusive. Nous avons identifié les facteurs qui contribuent dans les histoires de vie que ces professeurs construisent leur identité professionnelle, pour qu'ils prennent position comme des professeurs d'Éducation Spéciale. Nous avons pris la perspective historiqueculturelle comme référentiel théorique, surtout de Baktin et Vygotsky. Dans les entrevues collectives réalisées avec sept professeurs d'écoles publiques de Roraima, nous analysons le processus de constitution de leurs identités, considérant leurs histoires de vie personnelle, académique et professionnelle, identifiant l'influence marquante de la présente structure de l'organisation du travail du professeur dans leurs perfils professionnels.

Mots clefs: Éducation Spéciale. Formation de maîtres. Inclusion. Identité de professeur. Professionnalité du professeur.

\section{Educación especial en tiempos de educación inclusiva: la identidad docente en cuestión}

\section{Resumen}

Presentamos una pesquisa realizada durante una maestría en educación, en la cual buscamos comprender la forma como profesoras que actúan en la educación de personas con discapacidad, conocidos como profesores de la educación especial, constituyen su identidad profesional en ese momento en que las discusiones apuntan para el énfasis en la educación inclusiva. Identificamos los factores de las historias de vida de esas profesoras que contribuyeron para la construcción de su identidad docente y para que se posicionaran como profesoras de el área de educación especial. Tuvimos como referencial teórico la perspectiva histórico cultural, en especial los estudios de Bakhtin y Vygotsky. En las entrevistas colectivas realizadas con un grupo de siete profesoras de escuelas públicas de Roraima, analizamos el proceso de constitución identitaria de estas profesoras considerando sus historias de vida personal, académica y profesional, identificando la influencia marcante de la actual estructura de organización del trabajo docente en sus perfiles profesionales.

Palabras-clave: Educación especial. Formación de profesores. Inclusión. Identidad docente. Profesionalidad docente.

Recebido em: 07.10 .2008

Aceito em: 29.01.2009 